\title{
What the Neurosurgeon needs to know about Cerebral Developmental Venous anomalies
}

\author{
Hernando Raphael Alvis-Miranda ${ }^{1}$, Nancy Duarte-Valdivieso ${ }^{2}$, \\ Gabriel Alcala-Cerra ${ }^{3}$, Willem Calderon-Miranda ${ }^{4}$, \\ Marco Zenteno $^{5}$, Angel Lee ${ }^{6}$, Luis Rafael Moscote-Salazar ${ }^{1}$ \\ ${ }^{1}$ Universidad de Cartagena, Colombia \\ ${ }^{2}$ Chang Gung Memorial Hospital, Linkou, Taiwan \\ ${ }^{3}$ Neurosurgeon, Universidad de Cartagena, Colombia \\ ${ }^{4}$ Neurosurgeon, Universidad del Magdalena, Colombia \\ ${ }^{5}$ Instituto Nacional de Neurologia y Neurocirugia "Manuel Velasco Suarez", Mexico D.F, Mexico \\ ${ }^{6} \mathrm{Hospital}$ Angeles del Pedregal, Mexico, Mexico D.F
}

\begin{abstract}
Venous Angiomas or Developmental venous anomalies (DVA) are extreme variations of normal transmedullary veins that are necessary for the drainage of white and gray matter, also are one type of cerebrovascular malformation (CVM), sharing category with capillary telangiectesias, cavernous malformations (CM), and arteriovenous malformations (AVM), each of which may also be associated with a DVA. DVA are the most commonly encountered CVM, accounting for up to $60 \%$ of all CVM. We present a review of the literatura
\end{abstract}

Key words: Developmental venous anomalies, Venous Angiomas, neurointervention

\section{Introduction}

Developmental venous anomalies (DVA) are extreme variations of normal transmedullary veins that are necessary for the drainage of white and gray matter, also are one type of cerebrovascular malformation (CVM), (1) sharing category with capillary telangiectesias, cavernous malformations (CM), and arteriovenous malformations (AVM), each of which may also be associated with a DVA. (2) DVA are the most commonly encountered CVM, accounting for up to $60 \%$ of all CVM. Their prevalence is around 2.5$9 \%$, and they are usually solitary. (3)

Huang et al., in 1984 (4) analyzed the angiographic findings of DVA and proposed terming them "medullary venous malformations," and Russel and Rubinstein (5) defined cerebrovascular malformations as "cerebral vascular hamartomas" as intention to embrace malformations with a pathological process, however, the most accurate term, DVA, was first suggested by Lasjaunias and Burrows in 1986, (6), because venous 
malformations originate from persisting embryologic medullary veins related to alterations in the embryonic period; thus it has been used to describe what is also known as venous angioma, cerebral venous malformation, and cerebral venous medullary malformation. Abandonment of the other designations reflects the nature of the DVA, although the exact etiology remains unknown, does not involve endothelial proliferation, has no proliferative potential, no direct arteriovenous shunts, and generally normal brain parenchyma between the dilated veins. $(6,7)$

The use of current neuroimaging techniques has led to great advances in the diagnosis of CVM, and particularly the DVA diagnosis (1), the aim of this work is to review relevant issues regard DVA, which can help a better understanding of the natural course of this type of cerebrovascular malformation.

\section{DVA architechture}

An appropriate knowledge of the cerebral venous anatomy is necessary to understand how DVA is constituted and which can be the meaning of its architecture, thus next will be discussed briefly the cerebral venous anatomy.

\section{Cerebral venous anatomy}

\section{The superficial venous system:}

This system drains the outer 2 centimeters of white matter and cortex in centrifugal direction through subcortical and intracortical veins toward pial veins, cortical veins and then dural sinuses.

Subcortical veins are composed of three segments: medullary, arcuate and intracortical, in their traveling to the brain surfaces. White matter have also a superficial drainage provided by superficial medullary veins. The cortex's superficial drainage is predominatly from intracortical veins, which travel to join either pial or superficial cortical veins. Pial veins, which lays in the brain surface, deep to the pia matter, collect blood drained from intracortical, subcortical and superficial medullary veins. Pial veins coalesce into cortical veins and then toward a dural venous sinus.

\section{The deep venous system}

Also known as Galenic venous system, drains blood in centripetal fashion from the more central white matter and paraventricular nuclei through tributaries of the great cerebral vein to the straight sinus. The deep medullary veins perform the deep drainage of white matter, they connect with subependimal vein, and as they traverse in their travel converge into 4 zones: include (1) a superficial zone within the white matter just below the corticomedullary junction; (2) a candelabra zone formed by horizontal connections between deep medullary veins; (3) a palmate zone consisting of connections between very small deep medullary veins just superficial to the lateral ventricles; and (4) a subependymal zone that represents the convergence of the venous trunks that drain from the palmate zone. The internal cerebral veins (ICV) or the vein of Galen are the major collectors of the subependymal zone. The bilateral ICV converge at or near the midline along with the bilateral basal veins of Rosenthal and medial and lateral atrial veins to form a singular midline vein: the great vein of galen. 
The drained blood runs into the major dural sinuses: superior sagittal sinus (SSS), inferior sagittal sinus (ISS), lateral sinus (LS), cavernous sinus and straight sinus, and then to the internal jugular vein (IJV). Superficial venous system predominantly drains the SSS and the LS. Deep white matter and basal ganglia are drained by the deep venous system toward the vein of Galen. Between these two cerebral vein system can be found many anastomoses.

\section{DVA constitution}

DVA consist of radially oriented and converging dilated medullary veins, which drain centripetally into a transcerebral collector (enlarged transcortical or subependymal draining vein) that opens either into the superficial subcortical or deep pial veins. They are composed of angiogenically mature elements; indeed they are widely accepted to represent anatomic variants of normal venous drainage. (3) Histologically the veins are enlarged and sometimes hyalinized, but otherwise normal. (3)

Because of the absence of normal or subependimal veins draining outer zone of the white matter and the cortex to the pial veins, it is generated an abnormal venous arrange or disposition, in which is produced a reversing of the drainage pattern, i.e., instead of superficial venous drainage, the blood is drainage toward the deep subependimal veins, in a centripetally fashion. The deep venous territory, instead of draining blood centripetally from the more central white matter and paraventricular nuclei, drains blood in a centrifugal fashion toward either the pial veins or directly into a dural

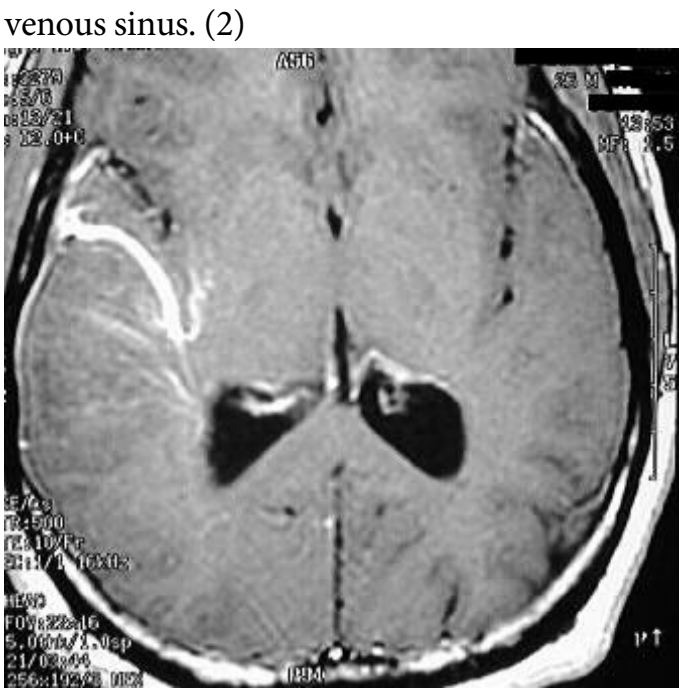

Figure 1 - Angio CT - venous angiomas on right side

Depending on their location, they may feed into the superficial (dural) or the deep venous systems. Posterior fossa DVA tend to direct venous blood to the veins of the lateral recess of the fourth ventricle, the precentral veins, a transpontine vein, or the longitudinal intrategmental vein, as detected by venous phase angiography. (8)

\section{Hypothesis}

Their etiology and mechanism of development are unknown, but it is currently accepted that they act like a compensatory system of cerebral parenchyma venous drainage due to early failure, abnormal development, or an intrauterine occlusion of normal capillaries or small transcerebral veins and thrombosis of normal parenchymal veins. (7) These drainage pathways may have developed as a method for maintaining the hemodynamic equilibrium of the transcortical venous drainage. According to Saito and Kobayashi (9), during embryogenesis, some 
accident occurs during the formation of the medullary veins or their tributaries, such as occlusion or maldevelopment, and as compensation results CVA, thus, the main suggested etiology for the formation of CVA is an embryologic accident that results in either arrested formation or thrombosis of the developing venous drainage of the specific region (10-12), that is followed by a secondary compensatory mechanism in which embryologic medullary venules persist and cluster locally in a large draining vein $(6,9,10$, 13). Thus, they may be better described as being the result of a fetal pathological event rather than true anatomic variations.

\section{Associated parenchymal abnormalities}

Although the parenchyma drained by a CVA is generally reported as normal brain tissue, there have been reports of parenchymal abnormalities in the vicinity, and they are more common than previously thought (2). The essential role of CVA in normal cerebral venous drainage is shown when cases of catastrophic venous ischemic and haemorrhagic complications arise as consequence from their surgical removal (14). Brain abnormalities found within the drainage territory of a CVA are (15): locoregional brain atrophy, which is observed in close to $30 \%$ of patients, followed by white matter, lesions (28.3\% on MRI, $19.3 \%$ on CT), CM (13.3\% of MRI investigations) and dystrophic calcification ( $9.6 \%$ of CT investigations).

To take into account, parenchymal abnormalities are equally observed in small-, medium-, and large-sized CVA, indicating that size is not a determining parameter for their development. Regard to the number of CVA, in the San Millán et al series, was observed that only $1.2 \%$ of patients harboured two coexisting CVA, a lower incidence than the $12 \%$ reported by Uchino et al (16).

The coexistence of two or more CVM within the same location has been documented (17-19). The prevalence of this specific subtype of mixed vascular malformations has a wide range, 2.1-25.9\% (20-22). Amongst these, the co-occurrence of CM and CVA has been reported most commonly $(15,21,23,24)$, almost up to $40 \%$ of CVA $(15,25,26)$, this fact generally explains presenting neurological symptoms if there is concordance with the location of a CVA and the $\operatorname{CM}(13,20,27)$.

Other parenchymal abnormalities, including signal modifications of white matter on magnetic resonance imaging (MRI) scans, dystrophic calcification and locoregional brain atrophy $(13,25,28)$, however with no clear information regard the significance of these findings.

DVA may also be present adjacent to brain tumors, infarcts, demyelinating areas, and moyamoya malformations; also associated congenital anomalies of the cerebral arterial system such as primitive trigeminal artery, fetal origin of the posterior cerebral arterial system, as well as fetal venous anomalies such as retention of the primitive falcial, occipital, and marginal tentorial sinuses, (29) lending credence to the theory that embryonic origin of CVS.

The neuropathologic changes underlying the radiographic changes associated with DVA or DVA-associated clinically significant syndromes are very poorly understood. Vaitkevicius et al (8) reported histopathologic evidence of vascular remodeling related to altered hemodynamics in the region of a DVA, including microvascular wall hyalinization 
DOI: 10.2478/romneu-2014-0019

and calcification, which are consistent with chronic regional blood flow alternation and venous hypertension.

\section{Clinical presentation}

CVA are usually asymptomatic, and are frequently discovered incidentally during medical imaging studies of the brain. $(3,15)$, probably because CVA generally provide sufficient venous drainage of the involved territory (2).

Sometimes DVA may present with headache, seizure, focal neurological deficit, dizziness, and ataxia. $(23,30,31)$ Symptoms can be produced either by venous congestion related to flow obstruction or mechanical compression (e.g., hydrocephalus or nerve compression). (32) The clinical sequelae of a CVA are likely related to the regional changes that occur near it.

As previously mentioned, CVA can be associated with cavernous venous malformations in up to $40 \%$ cases, and are considered now to be responsible for the vast majority of symptoms attributed to CVA in the pre-CT/MRI era $(33,34)$. CVA have been linked with ischemic or haemorrhagic infarctions, or with focal neurological symptoms $(28,35)$, probably due to stenosis or thrombosis of the collecting vein. Several authors have documented impaired brain perfusion attributed to venous congestion in areas drained both by small and large CVA $(36,37)$.

Garner et al. (31) retrospectively evaluated the risk of hemorrhage associated with DVA to be of $0.22 \%$ per year, while McLaughlin et al (33) prospectively found that risk to be of
$0.68 \%$ per year, though only half of their patients were symptomatic.

It was initially proposed that CVA located in the posterior cranial fossa had a higher propensity to bleed than supratentorial DVA, but that is not currently considered as truth. Only in about $25 \%$ of cases are CVA diagnosed because of the occurrence of epileptic seizures (38). Moreover, these lesions are often difficult to relate causally or topographically to the epileptogenic zone (19). More often they are occasionally observed during the diagnostic evaluation of different clinical pictures.

Pereira et al. (7) reviewed the pathomechanisms of symptomatic DVA. Based on imaging findings and clinical symptoms, two major pathomechanisms can be identified: mechanical and flow-related. Although mechanical complications lead either to hydrocephalus or to vessel-nerve conflicts, flow-related mechanisms can be further subdivided into those that are related to an increase in inflow into the DVA or to an obstruction of the outflow. See Tabel 1.

\section{Imaging}

The CVA is a large transparenchymal venous structure with many abnormal tributaries that converge into a larger vein, which in turn drains into a venous sinus (39, 40). The morphological hallmark of a CVA is a cluster of venous radicles that converge into a larger collecting vein, giving the CVA typical "caput medusae" appearance, demonstrable through both, CT and MRI, allowing confident diagnosis of CVA without the need to obtain digital subtracted angiography (DSA). (12) 
TABEL I

Pathomechanisms of symptomatic DVA

\begin{tabular}{|c|c|c|c|c|}
\hline \multirow{8}{*}{ 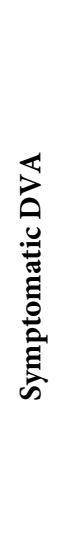 } & \multirow{3}{*}{ 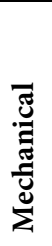 } & \multirow{2}{*}{ Hydrocephalus } & Interventricular foramen & \\
\hline & & & Aqueduct & \\
\hline & & $\begin{array}{l}\text { Neurovascular } \\
\text { compression }\end{array}$ & CN V, VII, VIII & \\
\hline & \multirow{5}{*}{ 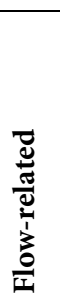 } & Increased inflow & Microshunt into DVA & \\
\hline & & & AVM draining into DVA & \\
\hline & & \multirow{3}{*}{ Dreased outflow } & \multirow{2}{*}{ Anatomical } & $\begin{array}{l}\text { Obstruction of the venous } \\
\text { collector }\end{array}$ \\
\hline & & & & $\begin{array}{l}\text { Obstruction of the draining } \\
\text { sinus }\end{array}$ \\
\hline & & & Functional & Distant high flow shunt \\
\hline
\end{tabular}

As mentioned previously, the collecting vein crosses the brain parenchyma to either join the superficial or deep venous system. (41)

Noncontrast CT may show a collecting vein as isodense or slightly hyperdense to cortex (11). Contrast-enhanced CT readily detects the draining vein of a CVA as a linear or curvilinear focus of enhancement that courses from the deep white matter to a cortical vein or to a dural sinus. (35)

However, because of its higher temporal resolution, DSA remains the best imaging modality to study the hemodynamic behavior of CVA. For this reason, DSA is performed in patients presenting with ischemic or hemorrhagic complications within the drainage territory of a CVA, or whenever an associated vascular malformation is suspected on CT or MRI $(2,12)$.

DVA have begun to be studied by resonance magnetic techniques, appearing as a hypointense signal globular or linear phase and hypo or hyperintense $\mathrm{Tl}-\mathrm{T} 2$ in the same way hyperintensity found surrounding parenchymal injury in $50 \%$ of cases. T1- and T2-weighted images demonstrate a characteristic parenchymal flow void corresponding to CVA. The enhancement of both the draining vein and the caput medusae may be seen also on gadolinium-enhanced T1weighted sequences. MRI is particularly useful and far superior to CT for the evaluation of related parenchymal abnormalities as well as for the detection of highly associated cavernous malformations (15).

Overall, developmental venous anomalies are low-flow vascular malformations, which are usually less conspicuous in conventional non-contrast MR images (42). Susceptibility weighted imaging is ideal for screening patients with a high clinical suspicion of lowflow vascular malformations (43) and limits the use of contrast studies and digital subtraction angiograms in their 
DOI: 10.2478/romneu-2014-0019

demonstration. State-of-the-art 320multidetector row CT (320-MDCT) is available in a few institutions and can perform dynamic subtracted CT angiography, allowing for morphologic as well as hemodynamic analyses of DVA.

\section{Arterialized DAV (venous predominant parenchymal AVMs or arterialized venous malformations)}

These are atypical DVA which are characterized by early angiographic opacification during the mid or later arterial phases, are also known as. (44) Although the pathogenesis of this subtype of DVA remains uncertain, they may represent a spectrum evolving from a simple DVA to a "classic" AVM, $(2,12)$ in which the DVA may serve as a foundation for future AVM development.

\section{Management}

Conservative management is strongly suggested (45). Their management requires a thorough understanding of the nature of CVA, including their frequent coexistence with other types of vascular malformation, and the existence of more complex but rare forms of presentation, such as the arterialized DVAs.

Indications for surgical removal are reserved for patients with large or recurrent hemorrhage, poorly controlled seizures, secondary trigeminal neuralgia or refractory to medical treatment, hemifacial spasm or hydrocephalus for aqueduct compression. (46)

Despite being the most frequent CVM, its treatment principles have not been established. A number of case series have reported a favorable outcome in DVA thrombosis after anticoagulation. (30, 47-53) Prevailing this benefit despite hemorrhage. $(48,51)$

Because most patients do well, no aggressive therapy, surgical or radiologic, needs to be performed. Failure to recognize this may cause needless anxiety and will result in potentially injurious treatment. It is certainly important to provide careful followup monitoring because aging can cause hemodynamic stress to DVA, causing possible occlusion and venous infarction.

\section{Correspondence}

Luis Rafael Moscote-Salazar, Universidad de Cartagena, Cartagena de Indias, Colombia.

E-mail:mineurocirujano@aol.com

\section{References}

1. Striano S, Nocerino C, Striano P, Boccella P, Meo R, Bilo L, et al. Venous angiomas and epilepsy. Neurol. Sci. Off. J. Ital. Neurol. Soc. Ital. Soc. Clin. Neurophysiol. [Internet]. Department of Neurological Sciences, Epilepsy Center, Federico II University, Naples, Italy.: Springer-Verlag Italia; 2000 Jun;21(3):151-5. Available from:

http://search.ebscohost.com/login.aspx?direct=true $\& d b$ $=$ mnh\&AN $=11076003 \&$ lang $=$ es\&site $=$ ehost-live

2. Pearl M, Gregg L, Gandhi D. Cerebral Venous Development in Relation to Developmental Venous Anomalies and Vein of Galen Aneurysmal Malformations. Semin. Ultrasound, CT MRI [Internet]. 2011 Jun;32(3):252-63. Available from:

http://www.sciencedirect.com/science/article/pii/S08872 1711100028X

3. Cakirer S. De Novo Formation of a Cavernous Malformation of the Brain in the Presence of a Developmental Venous Anomaly. Clin. Radiol. [Internet]. 2003 Mar;58(3):251-6. Available from: 
http://www.sciencedirect.com/science/article/pii/S00099 26002004701

4. Huang Y, Robbins A, Patel S, Chaudhary M. Cerebral venous malformations and a new classification of cerebral vascular malformations. Cereb. venous Syst. its Disord. Orlando: Grune \& Stratton; 1984.

5. Russell DS, Rubinstein LJ. Pathology of tumours of the nervous system. Arnold E, editor. London; 1989.

6. Lasjaunias P, Burrows P, Planet C. Developmental venous anomalies (DVA): the so-called venous angioma. Neurosurg Rev [Internet]. 1986 Jan [cited 2013 Apr 20];9(3):233-42. Available from:

http://www.ncbi.nlm.nih.gov/pubmed/3550523

7. Pereira VM, Geibprasert S, Krings T, Aurboonyawat T, Ozanne A, Toulgoat F, et al. Pathomechanisms of symptomatic developmental venous anomalies. Stroke [Internet]. 2008 Dec [cited 2013 Oct 11];39(12):3201-15. Available from:

http://www.ncbi.nlm.nih.gov/pubmed/18988912

8. Vaitkevicius H, Erdemli HE, Anderson WS, Zamani AA, Friedlander RM, Folkerth RD. Biopsy neuropathology of cerebral ischemia associated with a developmental venous anomaly. Clin Neurol Neurosurg [Internet]. 2013 May [cited 2013 Oct 13];115(5):621-3. Available from:

http://www.ncbi.nlm.nih.gov/pubmed/22771305

9. Saito Y, Kobayashi N. Cerebral venous angiomas: clinical evaluation and possible etiology. Radiology [Internet]. 1981 Apr [cited 2013 Apr 20];139(1):87-94. Available from:

http://www.ncbi.nlm.nih.gov/pubmed/7208947

10. Hong Y, Chung T-S, Suh S, Park C, Tomar G, Seo K, et al. The angioarchitectural factors of the cerebral developmental venous anomaly; can they be the causes of concurrent sporadic cavernous malformation? Neuroradiology [Internet]. 2010 Oct;52(10):883-91. Available from: 10.1007/s00234-009-0640-6

11. Ruíz DSM, Yilmaz H, Gailloud P. Cerebral developmental venous anomalies: current concepts. Ann Neurol [Internet]. 2009 Sep [cited 2013 Apr 21];66(3):271-83. Available from: http://www.ncbi.nlm.nih.gov/pubmed/19798638
12. San Millán Ruíz D, Gailloud P. Cerebral developmental venous anomalies. Child's Nerv. Syst. Chns Off. J. Int. Soc. Pediatr. Neurosurg. [Internet]. Neuroradiology Unit, Department of Diagnostic and Interventional Radiology, Hospital of Sion, Avenue du Grand-Champsec 80, 1951, Sion, Valais, Switzerland. diego.san-millan-ruiz@rsv-gnw.ch: Springer Verlag; 2010 Oct;26(10):1395-406. Available from:

http://search.ebscohost.com/login.aspx?direct=true\&db $=$ mnh\&AN=20703485\&lang=es\&site=ehost-live

13. Wilson CB. Cryptic vascular malformations. Clin Neurosurg [Internet]. 1992 Jan [cited 2013 Apr 20];38:49-84. Available from:

http://www.ncbi.nlm.nih.gov/pubmed/1537199

14. Senegor M, Dohrmann GJ, Wollmann RL. Venous angiomas of the posterior fossa should be considered as anomalous venous drainage. Surg Neurol [Internet]. 1983 Jan [cited 2013 Apr 20];19(1):26-32. Available from: http://www.ncbi.nlm.nih.gov/pubmed/6828991 15. San Millán Ruíz D, Delavelle J, Yilmaz H, Gailloud P, Piovan E, Bertramello A, et al. Parenchymal abnormalities associated with developmental venous anomalies. Neuroradiology [Internet]. Division of Interventional Neuroradiology, Johns Hopkins Hospital, 600 N. Wolfe Street, Baltimore, MD 21287, USA. dsanmil1@jhmi.edu: $\quad$ Springer-Verlag; 2007 Dec;49(12):987-95. Available from:

http://search.ebscohost.com/login.aspx?direct=true\&db $=\mathrm{mnh} \& \mathrm{AN}=17703296 \&$ lang=es\&site $=$ ehost-live

16. Uchino A, Hasuo K, Matsumoto S, Masuda K. Double cerebral venous angiomas: MRI. Neuroradiology [Internet]. 1995 Jan [cited 2013 Apr 20];37(1):25-8. Available from:

http://www.ncbi.nlm.nih.gov/pubmed/7708183

17. Hammoud D, Beauchamp N, Wityk R, Yousem D. Ischemic complication of a cerebral developmental venous anomaly: case report and review of the literature. J Comput Assist Tomogr [Internet]. 2002 [cited 2013 Apr 20];26(4):633-6. Available from:

http://www.ncbi.nlm.nih.gov/pubmed/12218833

18. Dillon WP. Cryptic vascular malformations: controversies in terminology, diagnosis, pathophysiology, and treatment. AJNR Am J 
DOI: 10.2478/romneu-2014-0019

Neuroradiol. [Internet]. 1997 [cited 2013 Apr 20];18(10):1839-46. Available from:

http://www.ncbi.nlm.nih.gov/pubmed/9403438

19. Awad IA, Robinson JR, Mohanty S, Estes ML. Mixed vascular malformations of the brain: clinical and pathogenetic considerations. Neurosurgery [Internet]. 1993 Aug [cited 2013 Apr 20];33(2):179-88; discussion 188. Available from:

http://www.ncbi.nlm.nih.gov/pubmed/8367039

20. Wilms G, Bleus E, Demaerel P, Marchal G, Plets C, Goffin J, et al. Simultaneous occurrence of developmental venous anomalies and cavernous angiomas. AJNR Am J Neuroradiol [Internet]. 1994 Aug [cited 2013 Apr 20];15(7):1247-54; discussion 1255-7. Available from: http://www.ncbi.nlm.nih.gov/pubmed/7976933

21. Perrini P, Lanzino G. The association of venous developmental anomalies and cavernous malformations: pathophysiological, diagnostic, and surgical considerations. Neurosurg Focus [Internet]. 2006 Jan [cited 2013 Apr 20];21(1):e5. Available from:

http://www.ncbi.nlm.nih.gov/pubmed/16859258

22. Abdulrauf SI, Kaynar MY, Awad IA. A comparison of the clinical profile of cavernous malformations with and without associated venous malformations. Neurosurgery [Internet]. 1999 Jan [cited 2013 Apr 20];44(1):41-6; discussion 46-7. Available from:

http://www.ncbi.nlm.nih.gov/pubmed/9894962

23. Töpper R, Jürgens E, Reul J, Thron A. Clinical significance of intracranial developmental venous anomalies. J Neurol Neurosurg Psychiatry [Internet]. 1999 Aug [cited 2013 Apr 20];67(2):234-8. Available from:

http://www.pubmedcentral.nih.gov/articlerender.fcgi?ar tid $=1736473 \&$ tool $=$ pmcentrez\&rendertype $=$ abstract

24. Zhang P, Liu L, Cao Y, Wang S, Zhao J. Cerebellar cavernous malformations with and without associated developmental venous anomalies. BMC Neurol [Internet]. 2013 Oct 3 [cited 2013 Oct 13];13(1):134. Available from:

http://www.ncbi.nlm.nih.gov/pubmed/24088363

25. Huber G, Henkes H, Hermes M, Felber S, Terstegge

K, Piepgras U. Regional association of developmental venous anomalies with angiographically occult vascular malformations. Eur Radiol [Internet]. 1996 Jan [cited 2013 Apr 20];6(1):30-7. Available from:

http://www.ncbi.nlm.nih.gov/pubmed/8797947

26. Crecco M, Floris R, Vidiri A, Squillaci E, Sergiacomi GL, Mattioli $M$, et al. Venous angiomas: plain and contrast-enhanced MRI and MR angiography. Neuroradiology [Internet]. 1995 Jan [cited 2013 Apr 20];37(1):20-4. Available from:

http://www.ncbi.nlm.nih.gov/pubmed/7708182

27. Rigamonti D, Spetzler RF, Medina M, Rigamonti K, Geckle DS, Pappas C. Cerebral venous malformations. J Neurosurg [Internet]. 1990 Oct [cited 2013 Apr 20];73(4):560-4. Available from:

http://www.ncbi.nlm.nih.gov/pubmed/2398388

28. Uchino A, Sawada A, Takase Y, Abe M, Kudo S. Cerebral hemiatrophy caused by multiple developmental venous anomalies involving nearly the entire cerebral hemisphere. Clin Imaging [Internet]. 2001 [cited 2013 Apr 20];25(2):82-5. Available from:

http://www.ncbi.nlm.nih.gov/pubmed/11483414

29. Pryor J, Setton A, Berenstein A. Venous anomalies and associated lesions. Neurosurg Clin N Am [Internet]. 1999 Jul [cited 2013 Oct 13];10(3):519-25. Available from: http://www.ncbi.nlm.nih.gov/pubmed/10419576

30. Lo S, Cheung Y, Tang K, Chan C, Siu C, Kwok K, et al. Non-haemorrhagic Pontine Venous Infarct due to Thrombosed Cerebellar Venous Angioma. J HK Coll Radiol. 2009;12:79-84.

31. Garner TB, Del Curling O, Kelly DL, Laster DW. The natural history of intracranial venous angiomas. J Neurosurg [Internet]. 1991 Nov [cited 2013 Apr 20];75(5):715-22. Available from:

http://www.ncbi.nlm.nih.gov/pubmed/1919693

32. Griffiths D, Newey A, Faulder K, Steinfort B, Krause M. Thrombosis of a Developmental Venous Anomaly Causing Venous Infarction and Pontine Hemorrhage. J. Stroke Cerebrovasc. Dis. [Internet]. (0). Available from: http://www.sciencedirect.com/science/article/pii/S10523 05713001614

33. McLaughlin MR, Kondziolka D, Flickinger JC, Lunsford S, Lunsford LD. The prospective natural history of cerebral venous malformations. Neurosurgery 
[Internet]. 1998 Aug [cited 2013 Apr 20];43(2):195-200; discussion 200-1. Available from:

http://www.ncbi.nlm.nih.gov/pubmed/9696070

34. Rigamonti D, Spetzler RF. The association of venous and cavernous malformations. Report of four cases and discussion of the pathophysiological, diagnostic, and therapeutic implications. Acta Neurochir [Internet]. 1988 Jan [cited 2013 Apr 20];92(1-4):100-5. Available from: http://www.ncbi.nlm.nih.gov/pubmed/3407463

35. Truwit CL. Venous angioma of the brain: history, significance, and imaging findings. AJR Am J Roentgenol [Internet]. 1992 Dec [cited 2013 Apr 20];159(6):1299307. Available from:

http://www.ncbi.nlm.nih.gov/pubmed/1442406 36. Tomura N, Inugami A, Uemura K, Hadeishi H, Yasui N. Multiple medullary venous malformations decreasing cerebral blood flow: case report. Surg Neurol [Internet]. 1991 Feb [cited 2013 Apr 20];35(2):131-5. Available from: http://www.ncbi.nlm.nih.gov/pubmed/1990481

37. Matsuda H, Terada T, Katoh M, Ishida S, Onuma T, Nakano H, et al. Brain perfusion SPECT in a patient with a subtle venous angioma. Clin Nucl Med [Internet]. 1994 Sep [cited 2013 Apr 20];19(9):785-8. Available from: http://www.ncbi.nlm.nih.gov/pubmed/7982312

38. Tannier C, Pons M, Treil J. [Cerebral venous angiomas. 12 personal cases and review of the literature]. Rev Neurol [Internet]. 1991 Jan [cited 2013 Apr 20];147(5):356-63. Available from:

http://www.ncbi.nlm.nih.gov/pubmed/1853033

39. Kraemer DL, Awad IA. Vascular malformations and epilepsy: clinical considerations and basic mechanisms. Epilepsia [Internet]. 1994 Jan [cited 2013 Mar 19];35 Suppl 6:S30-43. Available from:

http://www.ncbi.nlm.nih.gov/pubmed/8206013

40. Lasjaunias P. Vascular diseases in neonates, infants and children. Berlin Heidelberg New York: SpringerVerlag; 1997. p. 445-71.

41. Ruíz DSM, Gandhi D, Levrier O. Venous anomaly. J Neurosurg [Internet]. 2010 Jan [cited 2013 Apr 20];112(1):213-4; author reply 214. Available from: http://www.ncbi.nlm.nih.gov/pubmed/20043726

42. Somasundaram S, Kesavadas C, Thomas B. Susceptibility weighted imaging in holohemispheric venous angioma with cerebral hemiatrophy. Neurol. India [Internet]. Medknow Publications \& Media Pvt. Ltd.; 2008 Jan;56(1):104-5. Available from: http://search.ebscohost.com/login.aspx?direct=true\&db $=\mathrm{a} 9 \mathrm{~h} \& \mathrm{AN}=31208816 \&$ lang=es\&site $=$ ehost-live 43. Reichenbach JR, Jonetz-Mentzel L, Fitzek C, Haacke EM, Kido DK, Lee BC, et al. High-resolution blood oxygen-level dependent MR venography (HRBV): a new technique. Neuroradiology [Internet]. 2001 May [cited 2013 Apr 20];43(5):364-9. Available from:

http://www.ncbi.nlm.nih.gov/pubmed/11396739 44. Im S-H, Han MH, Kwon BJ, Ahn JY, Jung C, Park S$\mathrm{H}$, et al. Venous-predominant parenchymal arteriovenous malformation: a rare subtype with a venous drainage pattern mimicking developmental venous anomaly. J Neurosurg [Internet]. 2008 Jun [cited 2013 Oct 13];108(6):1142-7. Available from: http://www.ncbi.nlm.nih.gov/pubmed/18518718 45. Kondziolka D, Dempsey PK, Lunsford LD. The case for conservative management of venous angiomas. Can J Neurol Sci [Internet]. 1991 Aug [cited 2013 Apr 21];18(3):295-9. Available from: http://www.ncbi.nlm.nih.gov/pubmed/1913363 46. Abarca-Olivas J, Botella-Asunción C, ConcepciónAramendía LA, Cortés-Vela JJ, Gallego-León JI, Ballenilla-Marco F. [Two cases of brain haemorrhage secondary to developmental venous anomaly thrombosis. Bibliographic review]. Neurocir. [Internet]. 2009 Jun [cited 2013 Oct 13];20(3):265-71. Available from: http://www.ncbi.nlm.nih.gov/pubmed/19575131 47. Masson C, Godefroy O, Leclerc X, Colombani JM, Leys D. Cerebral venous infarction following thrombosis of the draining vein of a venous angioma (developmental abnormality). Cerebrovasc Dis [Internet]. 2000 [cited 2013 Oct 13];10(3):235-8. Available from: http://www.ncbi.nlm.nih.gov/pubmed/10773651 48. Merten CL, Knitelius HO, Hedde JP, Assheuer J, Bewermeyer $\mathrm{H}$. Intracerebral haemorrhage from a venous angioma following thrombosis of a draining vein. Neuroradiology [Internet]. 1998 Jan [cited 2013 Oct 13];40(1):15-8. Available from: http://www.ncbi.nlm.nih.gov/pubmed/9493181 
DOI: 10.2478/romneu-2014-0019

49. Thobois S, Nighoghossian N, Mazoyer JF, Honnorat J, Derex L, Froment JC, et al. [Cortical thrombophlebitis and developmental venous anomalies]. Rev Neurol [Internet]. 1999 Jan [cited 2013 Oct 13];155(1):48-50. Available from:

http://www.ncbi.nlm.nih.gov/pubmed/10093849

50. Walsh M, Parmar H, Mukherji SK, Mamourian A. Developmental venous anomaly with symptomatic thrombosis of the draining vein. J Neurosurg [Internet]. 2008 Dec [cited 2013 Oct 13];109(6):1119-22. Available from: http://www.ncbi.nlm.nih.gov/pubmed/19035729

51. Gama RL, Nakayama M, Távora DGF, Alvim TC de L, Nogueira CD, Portugal D. [Neuronal ceroid lipofuscinosis: clinical and neuroradiological findings].
Arq Neuropsiquiatr [Internet]. 2007 Jun [cited 2013 Oct 13];65(2A):320-6. Available from:

http://www.ncbi.nlm.nih.gov/pubmed/17607436

52. Prasad S, Hurst RW, Kasner SE. Postpartum thrombosis of a developmental venous anomaly. Neurology [Internet]. 2009 Jan 6 [cited 2013 Oct 13];72(1):92-3. Available from:

http://www.ncbi.nlm.nih.gov/pubmed/19122037

53. Brasse G, Stammel O, Siemens P, Töpper R. [Thrombosis of developmental venous anomaly and consecutive venous infarction]. Nervenarzt [Internet]. 2008 Jun [cited 2013 Oct 13];79(6):703-5. Available from: http://www.ncbi.nlm.nih.gov/pubmed/18389202 